Addressing Career Challenges Faced by Women in Hospitality Management

\author{
Judi Brownell \\ Cornell University
}

Published in Hospitality \& Tourism Educator (1993), $5(4), 11-15$ 


\section{Addressing Career Challenges Faced by Women in Hospitality Management}

In spite of the increasing number of women who are academically prepared for hospitality careers, women still appear to confront significant obstacles to their professional development. Women are leaving the hospitality industry at more than twice the rate of their male counterparts (Brownell, 1991), and, although better represented at managerial levels than ever before, fewer than 4\% of industry presidents and CEOs are women (Nelsen, 1990; Ettore, 1992). The question that has been asked so frequently for several decades now is. "Why?"

A body of literature documents the many issues associated with women in the work force generally, and with women in hospitality management in particular (Conlin, 1989; Marshall, 1989; Kenton, 1989). Studies on the glass ceiling (Bernstein, 1990; Ettore, 1992), old boy networks (Campbell, 1988; DeWine \& Casbolt, 1983), sexual harassment (diTomaso, 1989; Laudadis, 1988; Aaron \& Dry, 1992), and quality of work life issues (Lobel, 1991; Grummer, 1991; Cook, 1987) have made it clear that men and women often have significantly different organizational experiences. Without doubt, some of these experiences make it difficult for women to attain senior-level management positions. Consequently, a second question hospitality educators have begun 
to ask is, "What can be done within the context of academic environments to facilitate women's career development?"

The study reported here surveyed 287 women in middle-level hospitality management positions in domestic, full-service properties. Its purpose was to determine their perceptions regarding the most significant career-related obstacles to their professional development. Advice was also solicited pertaining to how hospitality educators might better prepare young women to meet the demands of a rapidly changing, fast-paced work environment. Based on the findings of this study, recommendations are made regarding how hospitality educators might encourage all of their students to engage in management practices that facilitate the professional development of women in the industry.

\section{Challenges of the Hospitality Environment}

Women in management face a number of gender-related challenges; several of these appear to be particularly significant for women in hospitality organizations, where, for a number of reasons, gender- related issues may be heightened.

As in other professions, women encounter old boy networks (DeLuca, 1988), which make it difficult for them to compete for senior-level management positions. Since most of the key decision makers are male, the personal contact so vital to 
gaining career-relevant information in the hospitality industry is more difficult for women than for men to establish. These informal liaisons are a source of advice and support that men have traditionally used to get ahead. Since women have significantly more difficulty connecting to these information sources, their professional development may be hampered as a result. Clearly, the "glass ceiling" has been the subject of much interest during the past several decades (Brophy \& Lennon, 1987; Melucci, 1989; Silberman, 1991). This glass ceiling has also resulted in a limited number of women available to serve as role models and mentors (Burke \& McKeen, 1990). When women look up, the view is still predominantly male.

It is also typical for hospitality management work to be characterized by long, irregular hours, often including evening or nighttime work. Promotions often require relocation, as well as taking on new and more time-consuming responsibilities. Women who have husbands and families are likely to confront significant quality-of-life issues as they attempt to balance their personal and professional lives. Gutek, Cohen, and Konrad (1990), for instance, proposed the notion of "sexualized" work environments, those in which gender differences are heightened due to an increased amount of anticipated physical contact on the job. Clearly, the responsibilities of hospitality employees often take them into places traditionally associated with 
social-sexual behavior such as bars, lounges, and bedrooms. Some authors, in fact, have suggested that instances of harassing behavior occur more frequently in hospitality contexts than in other types of work (Nozar, 1990; Eller, 1989).

There is no question that women pursuing hospitality management careers lace a number of challenges. The following section reports the results of a study (Brownell, 1993) which explored women's perceptions of these obstacles and their impact on career development.

\section{Survey Method and Results}

Self-administered questionnaires were sent to 389 women hospitality managers, all graduates of the same four-year academic program in hotel administration. All members of the sample held positions with titles of manager, supervisor, or director, and were graduated between 1964 and 1991. Respondents received an accompanying cover letter explaining the need for the study and describing the ways in which both the industry and the academic program might benefit from the requested information. Two hundred forty-four alumni initially responded; after a second mailing, a total of 287 usable surveys had been returned-a response rate of $81 \%$. The alumni affiliation may have contributed to an unusually high response rate. Although nonprobability sampling has inherent limitations, the common 
academic background of respondents was not judged to have a significant effect on their responses to questions pertaining to gender-related concerns.

An extensive literature review as well as focus groups of both male and female managers were employed to identify the gender-related obstacles perceived to be most significant to women's career advancement. From this investigation, it was determined that 11 factors appeared to recur as significant barriers: old boy networks, lack of women mentors, job characteristics, lack of role models, conflicts between family and work demands, equity in pay and in promotions, establishing credibility, sexual harassment, lack of training, and lack of job knowledge.

Women middle managers rated, on 6-point Likert scales, the degree to which they perceived each of these 11 factors as an obstacle to their personal career development. A rating of 1 indicated no obstacle, while a rating of 6 indicated that the respondent felt a particular item posed a very significant obstacle to her career advancement. Means and standard deviations were calculated for each item, as well as frequencies and percentages. Results of the survey are shown in Table 1. In addition, the women managers were asked to provide demographic information. Almost $80 \%$ of the respondents were under 35 years old: 28\% of the total sample were under 25 years 
old. Only 22\% of the women who responded were or had previously been married, and, of this group, less than 10\% had children.

Table 1. Perceived Obstacles to Career Success and Advancement by Women Hospitality Managers

Factor

Old boy network

Lack of women mentors

Job characteristics

Lack of role models

Family/work conflicts

Equity in pay

Equity in promotions

Establishing

credibility

Harassment

Lack of training

Lack of job knowledge
Mean

4.89

4.62

3.51

3.49

3.05

2.98

2.89

2.44

2.06

1.87

1.43
Standard Deviation

0.701

1.196

1.561

1.380

1.291

0.864

1.685

1.447

1.380

1.124

0.672

\section{Obstacles to Women's Career Development}

Respondents perceived old boy networks (mean 4.89), lack of women mentors (mean 4.62), and characteristics of the job (mean 
3.51) as the most significant barriers to their careers, while harassment (mean 2.06), lack of training (mean 1.87), and lack of job knowledge (mean 1.43) received the lowest ratings. Over two thirds of the women surveyed indicated that the old boy network and the lack of women mentors were "very significant" (rating of 6) obstacles.

Old Boy Networks

Women appear to be in agreement regarding the difficulties resulting from male-only information networks. As one woman wrote, "Information in the informal network is seldom passed on to women, as women are not included in the casual activities which promote information-sharing." Another women told of a recent incident in her workplace:

There are no women managers at our property, but there are three assistant managers. A week or so ago, several of the men were going out to a particularly nice restaurant for lunch. When the general manager was asked why none of the women assistant managers had been invited, his response was, "Well, this is business."

Such experiences clearly frustrate many women, and create barriers to further collaboration and problem-solving. 
Lack of Mentors

The issue of mentoring is also complicated by gender. A majority of the popular literature suggests that the problem stems from a lack of role models and mentors (Ragins \& Cotton, 1991: Noe, 1988). It appears, however, that it is not just that few women are senior-level managers; it is that those women who are in decision-making positions are not always perceived as supportive by other women. It has been found that most women develop satisfying relationships with male mentors and that they all too frequently describe negative experiences with their female colleagues and supervisors. Responses such as the following were typical:

- "My female boss doesn't have time to mentor or support me because she has to battle the old boy network to get to where she wants to be."

- "Women supervisors respond differently to me than to males. I think they feel more competitive with another woman. She expects more of me than of my male colleagues."

- "The senior-level females I know seem to have very few female friends. They feel they need to be 'one of the boys.' They're worried about their own survival." 
- "There are several women above me, but it is basically every women for herself. In fact, I have witnessed several incidents of actual back-stabbing among women trying to get ahead."

A troublesome number of respondents (84\% of those working in properties where a woman held a key management position) reported receiving little or no help or support and, in some cases, described a negative relationship with a senior-level female manager. The majority of women (87\% of the sample), however, lamented that there were simply no-or far too fewwomen role models within their organizations. 
Balance of Work and Family Life

Quality of life, as predicted, was another important concern. The issue, one respondent noted, is sacrifice: "Sacrifice is required of you if you want to stay in the profession-sacrifice of everything nonwork related." The cause of this conflict between work and family or personal life once again was attributed to long hours, frequent travel, and the relocations that become an inevitable consequence of promotion.

A large number of respondents (22\%) mentioned that they had to "work harder" than their male counterparts to get ahead. It appears that many of the women would agree that "the number of hours necessary to do the exceptional job we must do to be recognized cuts into family life drastically." As another respondent wrote, "Child care is my overwhelming concern. If meetings run long or corporate calls at 5:45 p.m. and you have to pick up your child by 6:00 p.m., you're in big trouble. I find that men don't understand my needs and have little sympathy." In spite of recent progress toward male participation, the burden of the family is still largely on the shoulders of women. 
Academic Preparation

A variety of suggestions were presented with regard to how students might best be prepared to meet the challenges of a demanding industry. Throughout, the recurring theme was finding ways to ensure that women would graduate with realistic expectations regarding such issues as work load and hours, salary, and general career progress. Women, respondents believed, need to get as much experience as possible in all areas of the industry. Internships and other work opportunities would help to keep students' expectations in line with the realities of the work place. Resoundingly, respondents advocated inviting practicing women managers to college campuses to talk with undergraduates about the realities of the work place. A significant number (48\%) of the women noted that students need visible role models-they need to hear for themselves what it's going to be like in the work world.

Many respondents (27\%) suggested courses designed specifically to focus on gender issues in hospitality management as one of the best ways to acquaint students-both men and womenwith industry needs. Opportunities could be provided to discuss not only problems but also potential solutions to the common barriers women confront (Christensen, 1987). The case-study method was advocated by several respondents as an appropriate teaching method. In addition, respondents believed greater 
emphasis on communication and other "people management" skills would be particularly helpful for future industry leaders. Career planning meetings and workshops that address gender concerns, and which help all students learn to set and formulate personal career goals, also were recommended.

\section{Preparing Students to Meet Industry Challenges}

If we listen to women in the industry, it appears that management educators can do a variety of things to facilitate women's career development. In addition to inviting women in the industry to talk with students, both in classes and in less formal settings, educators can also incorporate activities and introduce issues that address some of the most pressing genderrelated concerns into existing management courses.

Old Boy Networks

The old boy network raked highest on the list of challenges women confront. This issue can effectively be addressed in classrooms, first by ensuring that students understand the power of informal organizational channels, and then by introducing case studies and role plays to facilitate the application of these principles.

Studies of informal information networks have long emphasized the importance of informal channels within the more 
formal organizational structure. It is clear that informal networks are particularly significant in hospitality organizations, where employees depend heavily on social contacts for portions of their career- related information. If access to these networks is limited, and if most of the key opinion leaders are male, women clearly are at a disadvantage when it comes to informal information sharing. This situation is likely to affect their career development. Understanding how informal networks work and the role they play in disseminating information and strengthening interpersonal relationships is the first step in helping women become more active participants. Along with this knowledge, women must be helped to develop confidence in themselves and in their ability to interact effectively with their male colleagues and supervisors. Specific problems and situations can be defined through case studies, allowing both men and women an opportunity to consider various points of view and alternative strategies in dealing with difficult interpersonal communication situations. The richness of the case method allows a variety of organizational and personal factors to be considered in making choices about appropriate behavior. Open discussions allow students to explore sensitive issues in a nonthreatening environment. 
Role playing allows students to experiment with a variety of behaviors in response to recurring yet troublesome situations. For example, a situation might be described where a group of male managers have gathered together following a meeting. They are joking and laughing, planning a golf outing for the next day during which, it is evident, some of the important and pressing issues raised at the meeting will be discussed. The only woman manager is standing somewhat apart from the group. She realizes what is happening and knows that she will likely miss out on career-relevant information if she is excluded from this activity. What should she do?

On another occasion, a group of four male managers are having lunch in the employee cafeteria. A new, recently graduated woman manager walks by their table carrying a tray, obviously looking for a place to sit. The men say hello to her as she passes, but, although there is room at the table for another person, none of the men speak up to invite her to join them.

In this case, a number of factors are likely to be involved. The men may have assumed that she would feel uncomfortable as the only woman at the table.

They may have been enjoying their discussion of weekend football games and may have been reluctant to include a woman at their table, realizing that the topic of conversation would 
inevitably change. At least one of them, perhaps, was sensitive to recent harassment issues and was hesitant to make overtures to a young woman, fearing that they might be misinterpreted. In these and similar situations, both men and women can share their perceptions and practice appropriate responses. The consequences of their communication choices can also be discussed. Such consciousness-raising cannot help but smooth the way for future gender-related encounters.

\section{Mentoring}

The foundation for developing concerned and active mentors can be cultivated within the management classroom by discussing mentoring as a new management responsibility and by teaching skills related to coaching, counseling, and effective listening. Until the number of women in senior-level management increases, women will continue to rely on male mentors for help in their career development; both men and women must develop a commitment to encouraging women at work. Discussing issues related to cross-gender mentoring can be helpful in paving the way to smoother mentoring relationships.

Although mentoring continues to occur most frequently as an informal liaison between a senior-level manager and a promising protégé, it may be time to look carefully at the benefits of a more systematic and formalized mentoring system that is less 
likely to exclude women and other minorities. Guiding students in a discussion of the dimensions of mentoring and the ways in which it contributes to the professional development of both parties can be enlightening. Talking with students about their responsibility in identifying a mentor and developing a productive relationship with him or her will help them to approach their job responsibilities with increased confidence, and, as they advance in their careers, it will become essential for these same students to establish mentoring relationships with their employees.

Essential skills can be fostered by providing opportunities for students to practice handling the types of situations they are likely to encounter in the work place. Mentoring and coaching have become increasingly important aspects of a manager's job. No longer is it enough for well-qualified individuals to climb the professional ladder alone; successful managers are now defined as those who facilitate the career development of their employees as well.

The classroom context allows students to consider difficult questions in a supportive environment. Through cases or role plays, students might address some of the problems women face with regard to mentoring relationships:

- You are a woman who has been mentored by Tom Smith for over a year. A senior-level position opens up at another 
properly. Although Tom has talked about his interest in this position for months, corporate is anxious to promote women, and the VP of Personnel asks you to take the job. It is clear that you are neither as experienced or as well-qualified as Tom.

- You are a new woman manager at The Yorktown Hotel. After two months on the job, you have come to realize how dominant the male, "old boy" culture is at the 600-room property. You are particularly grateful, then, when Mark Tirone, one of the established male managers, shows an interest in your career development and takes you under his counsel. You begin to seek him out for advise on many of your decisions, and use your common lunchtime to chat. Recently, however, you realize that your behavior has fed the very active rumor mill. Stories of romance between you and Mark seem to have traveled throughout the property. The other women managers have been particularly cool lo you lately-it is clear that they think you are working your way to the top through questionable strategies. - You've been at the Double Inn almost three years and have made substantial career progress. One of the promises you made to yourself was that, once you were in the right position, you would do whatever you could to support and mentor other women. Karen, who was hired six months ago as assistant reservations manager, seemed to have a lot of potential. You spent a great deal of your time helping her learn your company's 
culture and expectations. As a result, she was quickly promoted. Lately, however, it seems that Karen has found herself a new mentor-a man who has more connections in the business than you do. Although you know it isn't really fair, you feel resentful and hurt that Karen no longer seeks your advice or shares her ideas and concerns with you. This all makes you very reluctant to take on such a responsibility again.

Although, as you can see from the above situations, mentoring is not without its challenges, it is an essential management task. Perhaps the most important skill in carrying out the role of mentor and coach is effective listening. Although speaking skills are critical to new employees who seek visibility and recognition, senior-level managers are, with increasing frequency, called on to listen intently to employees and customers alike to make wise decisions and solve complex problems (Brownell, 1990). Now yet another incentive has been added; effective listening is also key to effective mentoring. Listening skills can be developed within classroom contexts in a variety of ways, and must be fostered throughout students' academic careers (Brownell, 1992). Particularly within male/female contexts, students must develop empathy, overcome personal bias, and be able to view a situation from multiple perspectives. Resources-from textbooks to personal inventories 
to videotapes-are readily accessible (Brownell, 1986; Steil, Barker, \& Watson, 1983; Wolvin \&

Coakley, 1992; Wolvin \& Coakley, 1989) to assist students in developing these essential competencies. Several standardized assessment instruments also are available to those who would like additional information on their personal listening profile (Bostrom, 1983; Watson \& Barker, 1984). In an industry that relies so heavily on informal, interpersonal networks, the skills associated with mentoring are key to employees' professional growth.

\section{Job Characteristics and Quality of Life Issues}

Men and women alike need to be prepared for the "realities" of the work environment and be given opportunities to discuss the impact the unique characteristics of the hospitality industry-such as long hours and irregular shifts-may have on their personal lives. Issues ol relocation, child care, and other family-related concerns can best be presented in nonthreatening, academic situations. Useful questions are not difficult to generate:

- What do you do if you were planning on taking off Thursday afternoon to see your child's play, and suddenly you have to cover for two employees who didn't show up for their shift? 
- What happens when your husband, who has always supported your career, becomes increasingly depressed by your frequent late-night schedule and uncomfortable with the tact that the colleagues with whom you work and socialize are male?

- What do you do as a woman if your only foreseeable opportunity for promotion means asking your husband to leave his job and pulling your teenage children out of their school?

Guest speakers may be particularly helpful in addressing quality-of-life issues. Students can hear described, first hand, the kind of environment they may be entering. They can also engage in problem-solving discussions so that when they enter the workforce they will have a clear sense of the changes that need to take place to accommodate employees' needs. Increasing students' sensitivity to the balance hospitality employees must often keep between personal and professional activities may also prove helpful.

That this balance is more difficult for women- particularly women with families-comes as no surprise. The recognition that the industry is losing a large number of well-qualified employees because of quality-of-life issues, however, may motivate current students to seek better and more creative ways to reduce this conflict when they, as industry professionals, 
are faced with these challenges. There is no more appropriate place to engage in dialogue related to these and similar topics than in hospitality management classrooms. Inspired by the personal experiences of industry representatives and guided by well-informed instructors, students can explore some of the most pressing human resources management issues of the coming decade.

\section{Teamwork and Transformational Leadership}

Clearly, all students are stakeholders in the hospitality industry's future and will be affected by the nature and quality of the relationships that develop on the job. An understanding of informal networks, the development of skills in mentoring, and a heightened awareness and concern for quality-of-life issues are all vital lo effective management in a fast-paced, unpredictable environment.

The goal of hospitality education, however, is to do more than prepare students to deal effectively with current industry challenges. The men and women who graduate from hospitality programs and who go out into the industry must become leaders and change agents as they confront and attempt to resolve some of the problems women in the industry are facing.

In addition to addressing the specific challenges ahead, it may also be helpful to introduce students to the broader-based perspective into which these new competencies and understandings 
can be placed. Two characteristics of effective hospitality management in the 21st century are likely to be a passion for teamwork and transformational leadership (Baird \& Bradley, 1979; Epstein \& Bass, 1991; Rosener, 1990). What is particularly important to note is that both of these processes capitalize on nontraditional management styles-styles typically associated with more feminine approaches to management. Among the most significant characteristics of this new perspective are collaboration, sharing, interpersonal sensitivity, listening, and empowerment-all of which are skills and processes we have just proposed as essential outcomes of hospitality management curriculum.

Building high-performance teams will undoubtedly become, in the years ahead, one of management's most essential tasks. Effective team leaders recognize individual and group needs and respond in ways that facilitate productive outcomes. By capitalizing on the expertise of each member and on individual differences, effective group decision-making and optimal problem-solving result. A team approach recognizes common as well as individual goals, and builds trust and empathy across both individual and departmental boundaries. Women will likely be strong contributors and leaders in this process.

The skills required to build tomorrow's high- performance management teams are very different from those associated with 
earlier models. Autocratic, authoritative leadership behaviors have been replaced by careful listening, sensitivity to member needs, and an appreciation of member differences. This emphasis on a facilitative, empowering style is nowhere more apparent than in the behaviors of transformational leaders.

The transformational leader is distinguished by his or her emphasis on employee participation and involvement. These individuals lead by creating visions and motivating individuals to set and accomplish individual goals that are consistent with the larger organizational mission. Their organizations tend to be flatter. Emphasis is placed on developing cultures that support the expressed values of teamwork and diversity.

What impact will these new approaches have on genderrelated issues of hospitality management? Not only are women well-suited to become transformational leaders, but organizations led according to these principles would also be more comfortable, rewarding places for women to work and to develop their careers. The culture of such organizations may be characterized by just the ingredients women have indicated are so desperately needed in today's environments-open informationsharing, consistent coaching and mentoring, and sensitivity to quality-of-life issues. 


\section{Conclusion}

It is clear, from the study reported here and from related research, that women in hospitality management continue to face challenges in their career development. The good news is that there are a variety of ways in which hospitality educators can sensitize both men and women to the gender-related issues they will inevitably confront as they assume positions in hospitality organizations. Opportunities can be created lor industry representatives to talk with students, both in and out of the classroom, and to share their ideas and experiences. In addition to developing and offering special courses on women in management, educators can immediately address many important issues within the context of their current management classes. Through role plays, case studies, and open discussions, students can become more aware of the obstacles women confront and be better prepared to deal effectively with the realities of the hospitality work place. Within the context of a safe classroom environment, sensitive issues can be presented, and approaches to resolving gender-related problems can be experientially explored.

As hospitality management educators seek these opportunities to present information and activities that address gender-related concerns, they may also be facilitating the development of competencies that will characterize tomorrow's 
most effective hospitality leaders. Students' visions of what high-performance organizations look like must include women in leadership roles. There is no better place to create this shared vision than in today's hospitality management classrooms. 


\section{References}

Aaron, T., \& Dry, E. (1992). Sexual harassment in the hospitality industry. Cornell Hotel and Restaurant Administration Quarterly, 33(2). 93-95.

Baird, J. E., \& Bradley, P. H. (I979). Styles of management and communication. A comparative study of men and women. Communication Monographs. 46,101-111.

Bernstein, C. (1990). Unified effort vital to women's advancement: Stereotypes remain barrier to executive suite. Nation's Restaurant News. 24(25), 29.

Bostrom, R. N. (1983). The Kentucky comprehensive listening test. Lexington: Listening Research Center.

Brophy, B., \& Lennon, L. (1987). Why women execs stop before the top. US. News and World Report, p. 72 .

Brownell, J. (1993), Women hospitality managers: Perceptions of gender-related career challenges. Working paper, School of Hotel Administration, Cornell University, Ithaca, NY. Brownell, J. (1992). Preparing students for multi-cultural environments: Listening as a key management competency. Journal of Management Education, 16(5), 80-92.

Brownell, J. (1990). Perceptions of effective listeners: A management study. The Journal of Business Communication, $27(A), 401-415$ 
Brownell, J. (1991). Tracking study: School of Hotel

Administration, Cornell University. Unpublished manuscript.

Brownell, J. (1986). Building active listening skills. Englewood

Cliffs, NJ: Prentice-Hall.

Burke, R. J., \& McKeen, C. A. (1990). Mentoring in

organizations: Implications for women. Journal of Business Ethics, 9(4,5), 317-332.

Campbell, K. E. (1988). Gender differences in job-related networks. Work and Occupations, 15(2), 179-200.

Christensen, J. (1987). Educator's forum: Women in management:

Advice to recent graduates. Cornett Hotel and Restaurant Administration Quarterly 28(3), 48-49.

Conlin, J. (1989, March). Can men and women learn to

communicate? Successful Meetings, pp. 36A-36D.

Cook, M. F. (1987). Work and family: Juncture and disjuncture. ILR Report, 25 (1), 5-9.

DeLuca, M. (1988). Female lodging executives dealing with glass ceiling. Hotel \& Motel Management, 203(15), 10.

DeWine, S., \& Casbolt, D. (1983). Networking: External communication systems for female organizational members. The Journal of Business Communication, 20(2), 57-67. ditomaso, N. (1989). Sexuality in the workplace: Discrimination and harassment. In J. Hearn, G. Burrell, D. Sheppard, \& P. 
Tancred-Sheriff (Eds.), Sexuality in the organization (pp. 71-90). London: Sage Publications.

Eller, M E. (1989). Sexual harassment: Prevention, not protection Cornell Hotel and Restaurant Administration Quarterly, $90(4), 84-89$

Epstein, C F, \& Bass, B (1991, January/February). Ways men and women lead. Harvard Business Review, pp. 150-160.

Ettore. B. (1992, March). Women at work: Breaking the glass... or just window dressing? Management Review, pp. 16-22. Gummer, B. (1991). The management careers of men and women: Mommy tracks, daddy tracks and "new age" leadership. Administration in Social Work, $15(\mathrm{~A}), 111-128$.

Gutek, B A., Cohen. A. G., \& Konrad, A. M. (1990). Predicting social-sexual behavior at work: A contact hypothesis. Academy of Management Journal, 33(3), 560-577.

Kenton, S. B. (1989, Spring). Speaker credibility in persuasive business communication: A model which explains gender differences. The Journal of Business Communication, 26(2), 143-156.

Laudadis, D. M. (1988). Sexual and gender harassment: Assessing the current climate. Hospitality Education and Research Journal, $12(2), 411-415$. 
Lobel, S. A. (1991). Allocation ot investment in work and family roles: Alternative theories and implications for research. Academy ol Management Review, 16(3), 507-521.

Marshall, A. (1989). Women: The best solution to industry's talent shortage. Hotel and Motel Management, 204(15), 18$19,48$.

Melucci, L. (1989). Women at the top: There aren't many. Meeting News, $13(3), 1,52-54$,

Nelsen, B. J. (1990). Perceptions of sexism in F \& B oriented corporations. Lodging, 15(5), 51-52.

Noe, R. A. (1988). Women and mentoring: A review and research agenda. Academy ol Management Review, 13(1), 65-78.

Nozar, R. (1990). Winking at sexual harassment demeans lodging. Hotel and Motel Management, 205(7), 6-7.

Ragins, B. R., \& Cotton, J. L. (1991). Easier said that done: Gender differences in perceived barriers to gaining a mentor. Academy of Management Journal, 34(A), 939-951.

Rosener, J. (1990, November/December). Ways women lead. Harvard Business Review, pp. 119-125.

Silberman, R. G. (1991). A glass ceiling. Restaurant Hospitality, $75(6), 65$.

Steil, L. K., Barker, L. L, \& Watson, K. W. (1983). Effective Iistening: Key to your success. Reading, MA: AddisonWesley, 
Watson, K. W., \& Barker, L. L. (1984). Watson-Barker listening test. New Orleans, LA: Spectra, Inc.

Wolvin, A., \& Coakley, C. G. (Eds.). (1989). Experiential Listening: tools for teachers and trainers (1989). Auburn, AL: Spectra.

Wolvin, A., \& Coakley, C. G. (1992). Listening. Dubuque, IA: Wm. C. Brown. 